This item was submitted to Loughborough's Research Repository by the author.

Items in Figshare are protected by copyright, with all rights reserved, unless otherwise indicated.

Book review: image analysis, sediments and paleoenvironments

PLEASE CITE THE PUBLISHED VERSION

PUBLISHER

(C) Sage Publications

VERSION

AM (Accepted Manuscript)

LICENCE

CC BY-NC-ND 4.0

REPOSITORY RECORD

Graham, David J.. 2019. "Book Review: Image Analysis, Sediments and Paleoenvironments". figshare. https://hdl.handle.net/2134/5890. 
This item was submitted to Loughborough's Institutional Repository (https://dspace.lboro.ac.uk/) by the author and is made available under the following Creative Commons Licence conditions.

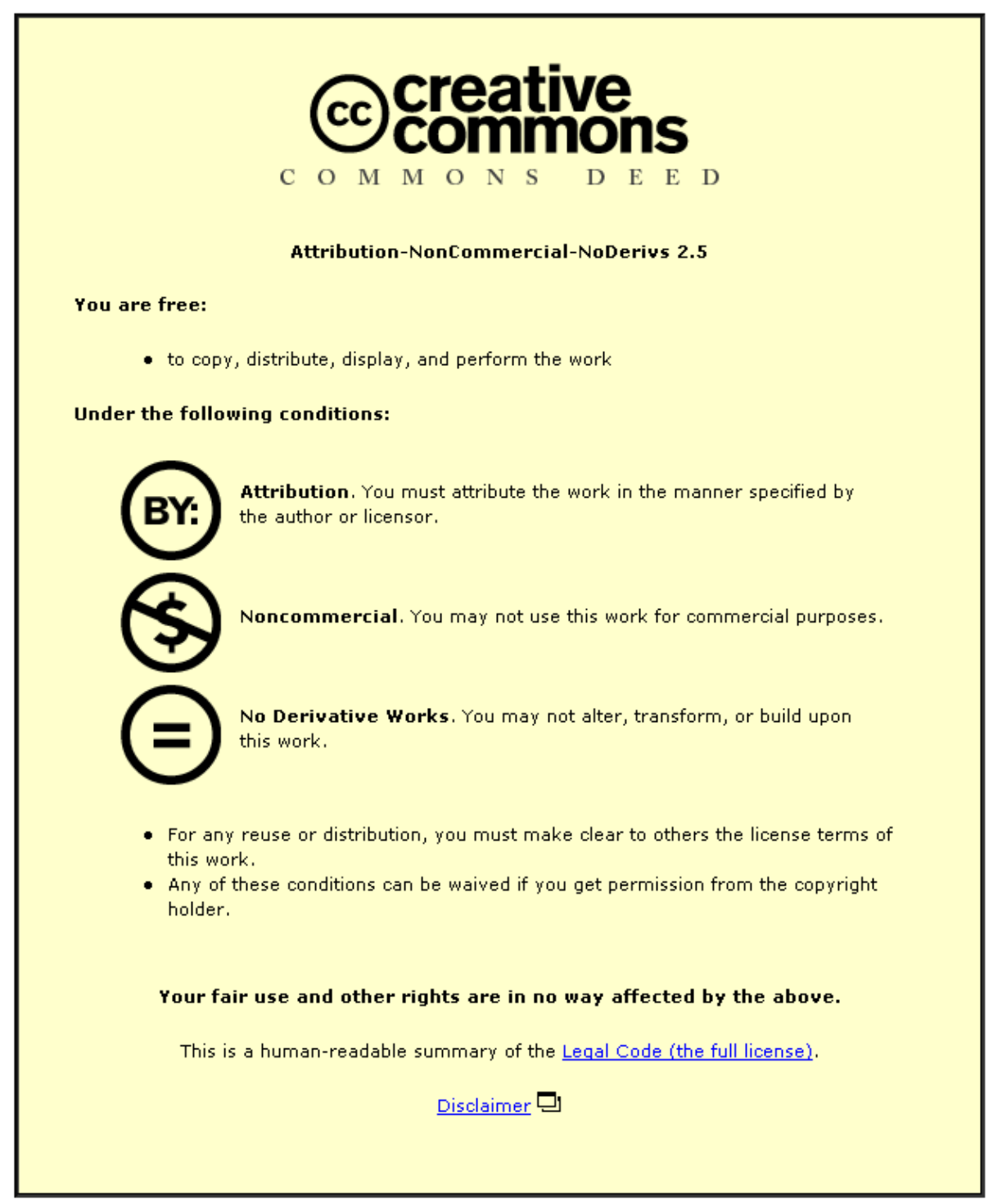

For the full text of this licence, please go to: http://creativecommons.org/licenses/by-nc-nd/2.5/ 


\section{[Book review]}

Image analysis, sediments and paleoenvironments (Developments in Paleoenvironmental Resaerch, Volume 7)

Edited by Pierre Francus, Dortrecht: Springer, 2004, 330 pp., €90, £63, US\$119, hardback, ISBN 1-4020-2061-9

The benefits associated with the application of digital image processing techniques have become increasingly accessible in recent years as data acquisition technology and computer processing power have dramatically improved. This book presents a showcase of what may be achieved by such techniques in the field of paleoenvironmental analysis and reconstruction.

Whilst not a proceedings volume in the conventional sense, this book is an outcome of the workshop on Image analysis: technical advances in extracting quantitative data for paleoclimate reconstruction from marine and lacustrine sequences held at the University of Massachusetts in 2001. The book is targeted at those who wish to apply such techniques as tools to assist with palaeoenvironmental reconstruction rather than image processing specialists. It is intended to fill the gap between the hard-core image-processing literature, which is frequently inaccessible to nonspecialist readers, and the sometimes over-generalised descriptions of procedures and protocols presented in the palaeoenvironmental research papers. Whilst the use of microscope slides and thin sections are discussed, the emphasis is on the analysis of sediment cores.

The book chapters are divided into three sections: the first presents a basic introduction to image analysis; the second presents a variety of examples of the practical application of these techniques; the third introduces more advanced techniques which the editor believes may be representative of some future directions of research. This tripartite approach is generally successful although, as is common with such edited volumes, there is some variability in the quality of the contributions. In addition, an extensive glossary represents an invaluable reference resource and prevents the need for repetition of basic definitions in each chapter.

The first section is essentially a textbook on those image-processing techniques with application in palaeoenvironmental reconstruction from sediment. The structure reflects the key stages in an image-processing project, with chapters on image acquisition (Lamoureux and Bollman), image correction and processing to identify the features of interest (Nederbragt et al.), and image measurement to extract data from the image (Pirard). A fourth chapter briefly discusses a variety of sources of error in derived measurements (Francus and Pirard). The material on sampling strategies in the chapter on image measurement was useful, but it would have been more logically located in the first chapter as sample design must be considered before image acquisition. Any attempt to summarise an entire discipline in ninety pages is bound to have omissions and simplifications and it is unreasonable to expect more than the bare bones of the subject to be presented. It will be necessary to refer to image processing texts for more detailed information. Notable omissions include discussion of mathematical morphology on greyscale images and the correction of spatial distortions. Nevertheless, the chapters provide a useful introduction to the 
principles and possibilities of image analysis in the context of sediment analysis and references to relevant further reading are included.

The second section presents a series of case studies illustrating how image analysis may be used extract useful palaeoenvironmental information from sediments. Contributions cover the use of colour (Prokoph and Patterson) and legacy greyscale photographs (Ortiz and O'Connell) and x-ray radiographs (Nederbragt and Thurow; Ojala; Principato) of sediment cores and electron microscopy of thin sections (Soreghan and Francus). The chapter on x-ray analysis of diamicton (Principato) stands in marked contrast to the others in that its analysis is unsophisticated, relying on numerous manual and subjective interventions by the operator. In addition, the case study presented is unconvincing, apparently demonstrating that the proposed method is unable to differentiate between diamictons produced by different processes. Because only one control sample of each sediment type is presented it is impossible to determine whether the samples are typical of the conditions they purport to represent. The chapter is also marred by some factual errors (e.g. sieve analysis does not measure the long-axis of grains). The remainder of the contributions provide useful and informative case studies of what may be achieved by image analysis.

The third section consists of three chapters examining the application of more advanced analysis techniques at the microscopic scale. The first two chapters focus on the automated classification of microfossils (Bollmann et al.) and pollen (France et $a l$.) using artificial neural networks. The final chapter provides an example of the use of wavelet analysis to examine what the variations in annual growth cycles recorded in the shells of freshwater mussels can reveal about environmental conditions (Verrecchia). All three contributions provide the reader with well-written and accessible introductions to material that is complex and involved. Whilst it will not be possible to immediately turn on a computer and apply these techniques, the chapters provide a useful starting point highlighting the key benefits and limitations of the techniques. Each is thoroughly referenced, so it should be easy to obtain additional information should the reader so desire.

Overall the volume is very well presented with numerous clear and informative illustrations. The quality of the English is a little variable, but the information is always clearly conveyed. The first section provides a concise introduction to many of the principles of image analysis, whilst the practical examples in the second and third sections should provide inspiration and ample practical guidance to those who wish to apply such techniques in their own research. Despite some reservations about a few aspects of the book, it represents an extremely useful starting point for academics and research students who wish to apply image analysis techniques to assist in the measurement of the properties of sediments.

David Graham

(Loughborough University) 